\title{
Incidence, Occurrence, Predisposing Factors and Etiology of Uterine Torsion in Buffaloes: A Review
}

\author{
M. Selvaraju ${ }^{1} *$ and C. Karthick ${ }^{2}$ \\ ${ }^{I}$ Veterinary University Training and Research Centre, Tamil Nadu Veterinary and Animal \\ Sciences University, Manmangalam (Post), Karur - 639 006, Tamil Nadu, India \\ ${ }^{2}$ Department of Veterinary Gynaecology and Obstetrics, Veterinary College and Research \\ Institute, TANUVAS, Namakkal - 637 002, Tamilnadu, India
}

*Corresponding author

\section{A B S T R A C T}

\section{Ke y w o r d s \\ Incidence, Occurrence, Etiology, Predisposing factors, Uterine torsion, Buffaloes \\ Article Info \\ Accepted: \\ 12 August 2020 Available Online: \\ 10 September 2020}

Uterine torsion is one of the common obstetrical problems encountered in buffaloes, if not treated properly may lead to death of the fetus subsequently the dam causing economic loss to the farmers. The occurrences of uterine torsion in buffaloes in relation to species, breed, parity, season, stage of gestation, side of torsion, site of torsion, degree of uterine torsion, duration of uterine torsion, fetal presentation, position and posture, sex of the fetus, livability of the fetus, survivability of the dam following detorsion, predisposing factors and etiological factors were reviewed.

\section{Introduction}

The domestic water buffalo (Bubalus bubalis) is an important livestock resource in many countries of Asia, the Mediterranean region and Latin America. The world population of buffalo is estimated to be 172 million (FAO: http://faostat.org/) of which 96 per cent (166 million) are in Asia and the remainder mainly in the Mediterranean and Latin American regions (Perera, 2008). Uterine torsion is recognized as a major obstetrical disorder in buffaloes causing dystocia (Srinivas et al., 2007) and caesarean section is the only choice to solve this disorder in delayed cases (Selvaraju et al., 2012). The occurrence of uterine torsion increases adrenocortical activity and influences blood vascular cellular components as well as the metabolism of liver, kidney and muscular system (Ghuman, 2010). Uterine torsion, first reported in 1766 by Boutrolle, is the rotation of the pregnant 
uterus on its longitudinal axis (Purohit and Gaur, 2014). It inflicts heavy economical losses to the farmers due to death of either fetus or dam or both beside impaired lactation (Prakash et al., 2018). A diverse list of contributing causes has been proposed including the anatomy, slipping or sudden fall, the manner by which the animal lies down and gets up and strong movements of the fetus during first stage of labor (Noakes et al., 2009). The etiology and pathogenesis of this condition is inadequately understood and remains open to speculation. Hence, the incidence, occurrence, predisposing factors and etiology of uterine torsion in buffaloes are reviewed in detail.

\section{Incidence of uterine torsion in bovines}

Torsion of the gravid uterus in bovines has been reported to be one of the major causes of dystocia in bovines (Siddiquee and Mehta, 1992 and Singh et al., 1992). In bovines, uterine torsion may involve uterine horn alone or uterine horn along with uterine body but former was rarely encountered (Dhaliwal et al., 1993). In buffaloes, incidences of 29.5 to 30.6 (Siddiquee and Mehta, 1992 and Amer et al., 2008), 52 to 70 (Purohit and Gaur, 2014), 67 to 83 (Malhotra, 1990; Singh, 1991 and Prabhakar et al., 1994) and 83.33\% (Srinivas et al., 2007) were recorded. In dairy cows, the reported incidences of uterine torsion between 3 and 10.7 per cent of dystocias were attended by general practitioners (Manning et al., 1982 and Laven and Howe, 2005). Out of 852 dystocias analysed from 2010 to 2015, the percentage of incidence of uterine torsion in cows and buffaloes was 13.97 and 27.46 (Karthick et al., 2015)

\section{Occurrence of uterine torsion}

\section{Species}

Occurrence of uterine torsion has been reported in various species viz., buffalo
(Selvaraju et al., 2014 and Karthick et al., 2016), cow (Prakash et al., 2014), doe (Manokaran et al., 2012), ewe (Velladurai et al., 2017), llama (Hopkins et al., 1991), camel (Cebra et al., 1997) and mare (Jung et al., 2008). Uterine torsion was also recorded in a bitch (Raut et al., 2008) and queen with pyometra (Stanley and Pacchiana, 2008) and even in laboratory species like rabbit (Hobbs and Parker, 1990) and guinea pig (Kunstyr, 1981).

Roberts (1986) stated that uterine torsion was occasionally observed as a cause for dystocia in beef cows, bitches, queens, ewes, does, and mares but rarely in sows. In dairy cows, it was observed more frequently than other species (Laven and Howe, 2005). But, Srinivas et al., (2007) reported that uterine torsion was the most important cause of maternal dystocia in buffaloes.

\section{Breed}

Brown Swiss cows were at a significantly higher risk, while Hereford, Angus and Jersey cows were at a lower risk for uterine torsion when compared with Holstein-Friesian cows (Frazer et al., 1996). Uterine torsion has been reported mostly in dairy type buffaloes of India (Selvaraju et al., 2014), Pakistan (Ahmed et al., 1981) and Egypt (El-Naggar, 1978) but reports on its occurrence in the swamp buffalo were not seen.

\section{Age/parity of the animal}

The influence of age on occurrence of uterine torsion remains controversial, as there was no age predisposition in uterine torsion affected buffaloes and cows of 2 to 18 years of age (Selvaraju et al., 2014 and Karthick, 2015). Pleuriparous buffaloes might be at greater risk of uterine torsion than primiparous (Selvaraju et al., 2014). The occurrences of uterine torsion in cows and buffaloes in relation to parity were 19.83 and $31.53 \%$ in primiparous 
cows and buffaloes and 80.17 and $68.47 \%$ in pleuriparous cows and buffaloes, respectively (Karthick et al., 2015).

\section{Season}

Frazer et al., (1996) stated that there was no effect of season on the incidence of uterine torsion in cows. However, they found the highest number of uterine torsion cases during peak calving period. Although a seasonal influence has been described in buffaloes, it appeared to be because of higher calving during that season (Purohit et al., 2011). The incidence was known to be more in cows maintained on mountainous areas (Singh, 1995). Roberts (1986) stated that the uterine torsion observed mostly during spring when cows were let onto pasture after prolonged stabling. As per the authors experience, occurrence of uterine torsion was more during October to February in cows and buffaloes in Namakkal District of Tamil Nadu.

\section{Stage of gestation}

The most striking aspect of bovine uterine torsion was that they almost invariably occurred at term and although the exact cause remains controversial. There was general agreement that most of the bovine uterine torsions occurred in association with first stage labor. This was based on the fact that in most cases a variable degree of cervical dilation was noted prior to or immediately after detorsion (Purohit and Gaur, 2014; Karthick et al., 2015).

Occasionally the cervix found to be fully dilated, with the membranes already ruptured. Thus, these cows actually entered the initial phase of second stage labor before the torsion developed (Selvaraju et al., 2014). However, uterine torsion from $5^{\text {th }}$ month of gestation also has been reported (Roberts, 1986). Prakash et al., (2018) reported the occurrence of uterine torsion at 75 days of gestation in graded Murrah buffaloes.

\section{Side of uterine torsion}

A preponderance of right side uterine torsion in buffaloes (95-98\%) (Srinivas et al., 2007 and Purohit et al., 2011) was postulated to be because of the absence of a muscular fold on right broad ligament in buffaloes (Brar et al., 2008) and the presence of the rumen on the left side (Purohit and Gaur, 2014).

Torsion to the left was generally associated with right horn pregnancy and vice versa because generally the gravid horn rolled toward and over the nonpregnant horn (Sloss and Dufty, 1980). Right sided postcervical uterine torsions at term were common in pleuriparous buffaloes (Srinivas et al., 2007). On the contrary, Frazer et al., (1996) and Aubry et al., (2008) reported higher incidence of counter-clockwise (left) torsion than clockwise direction in exotic cows. Karthick et al., (2015) found $91.61 \%$ and $72.34 \%$ right side uterine torsion in buffaloes and cows respectively.

\section{Site of torsion}

Most cases of uterine torsion were postcervical torsion (80\%) and only a few cases were precervical torsion (20\%) in buffaloes (Srinivas et al., 2007; Aubry et al., 2008; Amin et al., 2011 and Jeengar et al., 2015). Purohit et al., (2011) reported that the incidence of precervical uterine torsion was $83.60 \%$ in buffaloes. Similarly, in graded Murrah buffaloes, $14.19 \%$ precervical and $85.81 \%$ per cent postcervical uterine torsion was reported (Karthick et al., 2015).

The probable reason for higher incidence of postcervical uterine torsion could be because the anterior vagina is the weaker point of the bovine genital tract or due to the absence of 
the muscles in the cervical area of broad ligaments as opined by Jeengar et al., (2015).

\section{Duration of uterine torsion}

Selvaraju et al., (2014) stated that the duration of torsion was calculated based on the history provided by the farmer and the condition of the delivered fetus. Therefore, it was not unusual for uterine torsion to have occurred between 6 and more than 72 hours before the case was presented (Selvaraju et al., 2012). The estimated duration of labor in $63 \%$ torsions was between 8 and 12 hours and more than 12 hours in $21 \%$ uterine torsions (Manning et al., 1982). In another study, the percentage of uterine torsions presented in less than 6 hours, 6 to 24 hours, 24 to 48 hours, 72 to 96 hours and 96 to 168 hours after onset of torsion was 5, 55, 16, 17 and 7, respectively (Frazer et al., 1996).

\section{Degree of uterine torsion}

High (52.3\%), moderate $(31.0 \%)$ and mild $(16.7 \%)$ degrees of uterine torsion was reported in buffaloes (Ali et al., 2011). Roberts (1986) stated that minor torsions (45 to $90^{\circ}$ ) detected during routine pregnancy diagnosis underwent spontaneous correction. The severity of the uterine torsion was predominately 180 to $270^{\circ}$ (57 per cent) and 271 to $360^{\circ}(22 \%)$ (Frazer et al., 1996) in buffaloes. The percentages of uterine torsion with $<90^{\circ}, 90^{\circ}-180^{\circ}, 180^{\circ}-360^{\circ}$ and $>360^{\circ}$ were 12-21, 57-59, 12-28 and 3 in buffaloes, respectively (Singh et al., 1992 and Srinivas et al., 2007). About $49.10 \%$ cows and $51.52 \%$ buffaloes were affected with $90^{\circ}$ to $180^{\circ}$ uterine torsion (Karthick et al., 2015).

\section{Sex and weight of the fetus}

Uterine torsion noticed frequently in the case of male calves than female and the majority of uterine torsion was associated with the presence of an exceptionally heavy fetus (Frazer et al., 1996). On the contrary, uterine torsion was rare in cases of feto-pelvic disproportion (Aubry et al., 2008). The calves born after detorsion had 30 to $50 \mathrm{~kg}$ body weight according to the stage of pregnancy (30 kg at 7 month of pregnancy to $50 \mathrm{~kg}$ at full term) with more male than female calves in bovines (Amin et al., 2011). Similarly, 67.57 and $60.55 \%$ male fetus and 32.43 and $39.45 \%$ female fetus in cows and buffaloes affected with uterine torsion (Karthick et al., 2015). The majority of the calves delivered were male (63 to 72.72 percent) in buffaloes following detorsion (Kanakapur et al., 1999; and Shiv Prasad et al., 2000).

\section{Fetal presentation, position and posture}

Sloss and Dufty (1980) reported that abnormal presentation could not be a factor in the development of uterine torsion. In fact, 80 to 100 per cent calves from uterine torsion affected bovines usually delivered in anterior presentation with majority in dorso-ilial (17 per cent) or dorso-pubic (43 per cent) position (Prabhakar et al., 1994; Frazer et al., 1996; Noakes et al., 2009; and Aubry et al., 2008). Roberts (1986) stated that the calf mostly was in the dorso-pubic presentation in cows with at least a rotation of $180^{\circ}$ and dorso-ilial presentations were commonly found in torsions of $240^{\circ}$.

\section{Livability of fetus}

Frazer et al., (1996) delivered only 24 per cent of the calves alive following detorsion in bovines. In their study, the condition of the dead fetuses ranged from fresh to autolytic, with 14 per cent being described as emphysematous. Ali et al., (2011) recorded that fetal and maternal mortalities occurred in 78.6 and 23.8 per cent following uterine torsion in buffaloes, respectively. They also stated that the stage of pregnancy and degree 
and duration of uterine torsion were major risk factors for fetal mortality, while the stage of pregnancy and fetal viability were important risk factors for maternal mortality. Live fetuses of 45.95 and 46.79 per cent and dead fetuses of 54.05 and 53.21 per cent in respectively were extracted following detorsion in cows and buffaloes. The high rates of live fetal delivery when compared to the previous reports might be due to the availability of expertise, prompt diagnosis and timely intervention in our clinics (Karthick et al., 2015).

\section{Survivability of dam}

The survivability rate following detorsion in cows and buffaloes was 86.55 and 88.46 per cent respectively (Karthick, 2015). This finding was in accordance with the reports of Sloss and Dufty (1980) and Frazer et al., (1996) in bovines. However, Amer and Hashem (2008) found the dam survival rate as 69.00 per cent in bovines. Major factor played a role in the survivability of dam might be the time elapsed between the occurrence of torsion and its correction (Prabhakar et al., 1994). The death of the dam in uterine torsion affected buffaloes was attributed to development of uterine edema and ischaemic necrosis which led to endotoxic shock (Sloss and Dufty, 1980 and Manning et al., 1982), severe uterine necrosis, fetal putrification, maternal toxemia, dehydration, shock and peritonitis (Selvaraju et al., 2014).

\section{Predisposing factors}

Manning et al., (1982) and Roberts (1986) reported that during pregnancy, there was a relatively small increase in the length of the broad ligaments causing the uterus to curve around the point of attachment, coming to lie between the rumen, intestines and abdominal wall. This anatomical arrangement permitted an increased uterine mobility in late gestation and predisposed to development of a uterine torsion (Sloss and Dufty, 1980 and Roberts, 1986). Amer et al., (2008) stated that even in the last months of pregnancy, when horn asymmetry became maximal, uterine torsion was an exception rather than the rule.

A large number of predisposing causes have been described for uterine torsion which included (i) anatomical factors especially broad ligament attachment (ii) close confinement (iii) hilly tracts (iv) external injury (v) wallowing habits of the buffaloes (vi) the lowering of front legs by the animal first, when lying down (vii) excessive fetal weight (viii) deep capacious and pendulous abdomen of the buffalo (ix) inherently weaker muscles of the broad ligaments (x) the amount of fetal fluids in relation to the size of the fetus resulting strong fetal movements and (xi) parity (Purohit et al., 2011; Amer et al., 2008 and Ghuman, 2010).

\section{Etiology}

Several etiological factors have been contemplated to have direct or indirect effects viz., (i) geographical location (Roberts, 1986) (ii) husbandry practices (Ahmed et al., 1981) (iii) fetal weight and sex (Karthick et al., 2015) (iv) travel/accidents in advanced stage of pregnancy (Brar et al., 2008) (v) secondary to rolling because of a gastro-intestinal problem or following some traumatic incident (Taylor et al., 1989) (vi) weaker broad ligaments, smaller quantity of fetal fluids and decrease in uterine tone coupled with inordinate fetal movements (Purohit and Gaur, 2014) (vii) instability of the uterus during a single horn pregnancy and inordinate fetal or dam movements (Purohit et al., 2011) (viii) external injury, lack of exercise and irregular movement of animals (Selvaraju et $a l ., 2014$ ) and (ix) uterus didelphys (Singh et al., 1991). 
In conclusion, uterine torsion also occurred in prepartum period even at 75 days of gestation. Buffaloes are commonly affected than cows. Gestation with male calf makes the dam susceptible to uterine torsion. Availability of expertise, prompt diagnosis and timely intervention and treatment increases the survivability of the dam and fetus following detorsion in buffaloes.

\section{References}

Ahmed, M., Chaudhary R.A. and.Khan, H. (1981). Torsion of uterus as a cause of dystocia in the buffalo. Pakistan Veterinary Journal, 1: 22-24.

Ali, A., Derar R., Hussein, H.A., Abd Ellah M.R., and Abdel-Razek, A.K. (2011). Clinical, hematological and biochemical findings of uterine torsion in buffaloes (Bubalus bubalis). Animal Reproduction Science, 126: 168-172.

Amer, H.A., and Hashem, M.A. (2008). Relationship between clinical and biochemical picture of uterine torsion in Egyptian buffaloes (Bubalus bubalis). The International Journal of Veterinary Medicine, 4: 101-105.

Amer, H.A., Hashem M.A., and Bader, A. (2008). Uterine twisting during pregnancy in buffaloes: relationship between clinical findings and biochemical indices. Journal of Applied Biological Sciences., 2: 31-39.

Amin, S.M., Amer, H.A., Hussein A.E., and Hazzaa, A.M. (2011). Creatine phosphokinase and aspartate aminotransferase profiles and its relation to the severity of uterine torsion in Egyptian buffalo. Animal Reproduction Science, 123: 163-168.

Aubry, P., Warnick, L.D., DesCoteaux L., and Bouchard, E. (2008). A study of 55 field cases of uterine torsion in dairy cattle. Canadian Vet. J., 49: 366-372.

Brar, P.S., Saigal, R.P., Nanda A.S., and
Sharma, R.D. (2008). Role of broad ligament in the causation of uterine torsion in dairy buffaloes. Indian Journal of Animal Sciences, 78: 940942.

Cebra, C.K., Cebra, M.L., Garry F.B., and Johnson, K. (1997). Surgical and nonsurgical correction of uterine torsion in new world camelids; 20 cases (19901996). J. American Veterinary Medical Association, 211: 600-02.

Dhaliwal, G.S., Prabhakar S., and Sharma, R.D. (1993). Torsion of pregnant horn in a cow-A case report. Indian Journal of Animal Reproduction, 14: 129.

El-Naggar, M., (1978). Evaluation of field oriented treatment of uterine torsion in buffaloes in Egypt. Indian Veterinary. Journal, 55: 61-67.

Frazer, G.S., Perkins N.R., and Constable, P.D. (1996). Bovine uterine torsion: 164 hospital referral cases. Theriogenology, 46: 739-758.

Ghuman, S.P.S., (2010). Uterine torsion in bovines: a review. Indian Journal of Animal Sciences., 80: 289-305.

Hobbs, B.A. and Parker, R.F. (1990). Uterine torsion associated with either hydrometra or endometritis in two rabbits. Laboratory Animal Science, 40: 535-36.

Hopkins, S.M., Althouse, G.C., Jackson L.L., and Evans, L.E. (1991). Surgical treatment of uterine torsion in a llama (Lama glama). Cornell Veterinarian, 81: 425-428

Jeengar, K., Choudhary, V., Maharia, S.,Vivekanand and Purohit, G.N. (2015). A retrospective study on type and extent of uterine torsion in buffaloes. Research Journal of Veterinary Practitoners, 3: 25-28.

Jung, C., Hospes, R, Bostedt, H., and Litzke, L.F. (2008). Surgical treatment of uterine torsion using a ventral midline laparotomy in 19 mares. Australian 
Veterinary Journal, 86: 272-76.

Kanakapur, D.K., Krishnaswamy, A.and Debey, B.M. (1999). Studies on some factors influencing treatment and maternal recovery rate in uterine torsion among crossbred dairy cattle. Indian Journal of Animal Reproduction, 20: 31-32.

Karthick, C., (2015). Influence of haematobiochemical, hormonal and histopathological changes of placentomes in buffaloes affected with uterine torsion. M.V.Sc., Thesis submitted to Tamil Nadu Veterinary and Animal Sciences University, Chennai.

Karthick, C., Selvaraju, M. Ezakial Napolean R. and Doraisamy, K.A. (2016). Hematological changes during uterine torsion and detorsion in buffaloes. Indian Veterinary Journal, 93(10):2225.

Karthick, C., Selvaraju, M., Ezakial Napolean, R., and Doraisamy, K.A. (2015). Incidence of uterine torsion and its occurrence in relation to various factors in cows and buffaloes. Indian Journal of Animal Reproduction, 36 (2); 60-63.

Kunstyr, I., (1981). Torsion of the uterus and the stomach in guinea pigs. Zeitschrift fur Versuchstierkunde, 23: 67-69.

Laven, R. and Howe, M. (2005). Uterine torsion in cattle in the UK. Veterinary Record, 157: 96.

Malhotra, P., (1990). Some studies on the cervical changes in the uterine torsion cases with special reference to cervical filtration in buffaloes. M.V.Sc., thesis submitted to Punjab Agricultural University, Ludhiana, India.

Manning, J., March, P., Marshall, F., McCorkell, R., Muzyka, B., and Nagel, D. (1982). Bovine uterine torsion: A review illustrated by cases from the Western College of Veterinary Medicine Large Animal Clinic. Bovine
Practice, 17: 94-98.

Manokaran, S., Selvaraju M., Palanisamy M., and Ezakial Napolean, R. (2012). Uterine torsion in bicornual pregnancy in a goat. Indian Veterinary Journal, 89: $88-89$

Noakes, D.E., Parkinson, D.J. and England, G.C. (2009). Maternal dystocias. Arthur's Veterinary Reproduction and Obstetrics, $9^{\text {th }}$ edn. W.B. Saunders company. pp. 324-356.

Perera, B.M., (2008). Reproduction in domestic buffalo. Reproduction in Domestic Animals, 43: 200-206.

Prabhakar, S., Singh, P., Nanda, A.S. and Sharma R.D. (1994). Clinico-obstetrical observations on uterine torsion in bovines. Indian Veterinary Journal, 71: 822-824.

Prakash, S., Selvaraju, M., Ravikumar, K, Palanisamy, M., Manokaran, S., and Ezakial Napoleon, R. (2018). Surgical management of right post cervical uterine torsion during 75 days of gestation in a graded Murrah buffalo. Buffalo Bulletin, 37(1): 93-96.

Prakash, S., Selvaraju, M.and Ravikumar, K. (2014). Clinical management of postcervical Uterine torsion in a cow. Intas Polivet, 15(2): 241-242.

Purohit, G.N. and M.Gaur, (2014). Uterine torsion in buffaloes: A critical analysis. Buffalo Bulletin, 33: 363-378.

Purohit, G.N., Barolia, Y., Shekher C., and Kumar, P. (2011). Diagnosis and correction of uterine torsion in cattle and buffaloes. Raksha Technical Review, 2: 11-17.

Raut, B.M., Raghuwanshi, D.S., Upadhye, S.V., Galod, B.M., Gawande, A.P., Sirsat P.R., and Wankhade, P.R. (2008). Uterine torsion in a bitch. Veterinary World, 1: 212.

Roberts, S.J., (1986). Diseases and accidents during the gestation period. Diagnosis and treatment various types of dystocia. 
Injuries and diseases of the puerperal period. In: Veterinary Obstetrics and Genital Diseases (Theriogenology), Woodstock. VT: pp: 230-359.

Selvaraju, M. Manokaran, S., Prakash, S., Ravikumar, K. and Palanisamy, M. (2014). Bovine Obstetrical management in field practice. Proceedings of Kerela Veterinary Science Congress, pp.175179.

Selvaraju, M., Palanisamy M., Ravikumar, K., Manokaran, S., and Ezakial Napolean, $R$ (2012).Uterine torsion and fetal maceration in a crossbred cow. Indian Veterinary Journal, 89: 107-108

Shiv Prasad, Kumar R., and Maurya, S.N. (2000). Efficacy of laparohysterotomy and rolling of dam to treat uterine torsion in buffaloes. Indian Veterinary Journal, 77: 784-786.

Siddiquee, G.M. and B.M. Mehata, (1992). Uterine torsion in a buffalo with viable twins. Indian Veterinary Journal, 69: $257-258$

Singh, P. (1991). Studies on broad ligament in relation to uterine torsion in buffaloes. M.V.Sc., thesis submitted to Punjab Agricultural University, Ludhiana, India.

Singh, P. (1995). Recent observations on etiology and treatment of uterine torsion in buffaloes. In: Nanda, A.S. (edn.) Recent Advances in Animal Reproduction and Gynaecology. USG Publishers and Distributors, Ludhiana,
India. pp. 137-141.

Singh, V.K., Sharma, R.D., Dhaliwal, G.S., Gandotra, V.K., and Prabhakar, S. (1992). Uterine torsion in cows- An analysis of 34 cases. Indian Veterinary Journal, 69: 281-282.

Sloss, V. and Dufty, J.H. (1980). Obstetrical Physiology. Obstetrical Pathology. Obstetrical procedures. In: Sloss and Dufty (edn.,) Handbook of Bovine Obstetrics. Baltimore: Williams and Wilkins, pp. 108-111, 180-183.

Srinivas, M., Sreenu, M., Lakshmi Rani, N., Subramanyam Naidu, K., and Devi Prasad, V. (2007). Studies on dystocia in graded murrah buffaloes: A retrospective study. Buffalo Bulletin, 26: 40-45.

Stanley, S.W., and Pacchiana, P.D. (2008). Uterine torsion and metabolic abnormalities in a cat with a pyometra. Canadian Veterinary Journal, 49: 398400.

Taylor, T.S., Varner, D.D., Martin, M.T., Blanchard, T.L., Scrutchfield W.L., and Elmore, R.G. (1989). Management of dystocia in mares: uterine torsion and cesarean section. Compendium of Continuing Education for Practicing Veterinarian, 11: 1265-1273.

Velladural C, Selvaraju, M., and Ezakail Napolean R. (2017). Schaffer's method for the treatment of an ewe with uterine torsion. Indian Journal of Animal Reproduction, 38(1): 106-107.

\section{How to cite this article:}

Selvaraju, M. and Karthick, C. 2020. Incidence, Occurrence, Predisposing Factors and Etiology of Uterine Torsion in Buffaloes: A Review. Int.J.Curr.Microbiol.App.Sci. 9(09): 1326-1333. doi: https://doi.org/10.20546/ijcmas.2020.909.162 